\title{
Adding E-books to Your Catalogue
}

Helen Greenwood



Allowing patrons to access

full text e-books via the John Kinder

Theological College catalogue (Anglicat)

Full text e-books from the NZ Electronic Text Centre (NZETC) www.nzetc.org

Early New Zealand Books (ENZB)

www.enzb.org.nz 


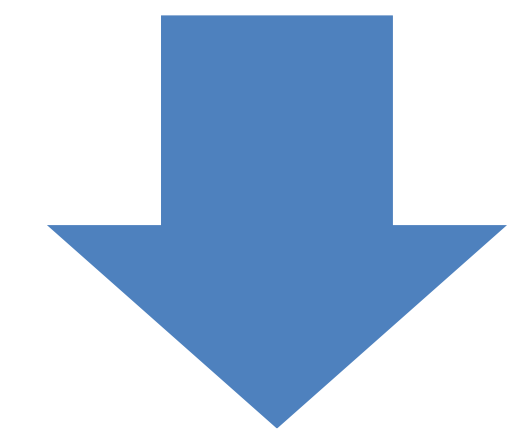

\section{Attach to existing record for print version (if held)?}

Create new record for electronic resource?

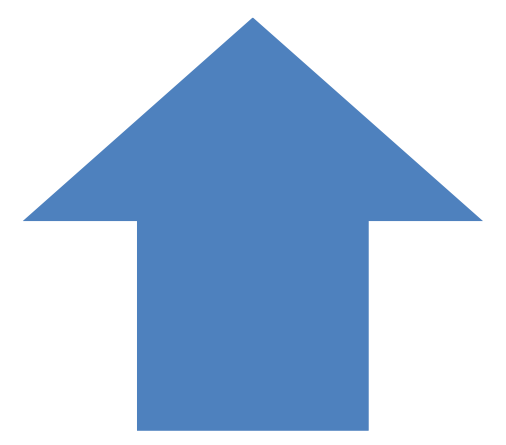

\section{AUTOCAT}

- Listserv discussing cataloguing issues

- To join, go to http://listserv.syr.edu/archives/autocat.html

- Has a searchable archive 
While it can be confusing for patrons to view multiple hits for the same title in a browse screen, I have found that it is much more confusing from a collections management view point to have print and electronic formats represented on one selector

work

techı "Not sure what Ist the

print "Not sure what I would do if we already had $t$ realize is

avail a history of combining formats on one quently

whol record, but I could never recommend starting t route for

the $r$ reate

sepa the practice now." it.

Not

recol

ts on one

Chris

Chris Blackman

Catalog Librarian

Williams College Libraries

Posted on Autocat 11 December 2008

There aren't any easy answers for this one. There is/was a general thought that multiple records for different formats present a source of confusion or frustration to users. Many libraries have opted for the "single record" approach in the past (including my own). This was particularly useful in the era of text-based OPACs,

al

$\mathrm{m}$

N "Libraries of all sizes are discovering that the

e) "separate record" approach adopted by large

$m$
$a$ research libraries (for both pragmatic and principled

$\underset{r \epsilon}{\text { at }}$ reasons, and established as the "correct" approach),

$\begin{array}{lll}r \in & \text { reasons, and established as the "correct" approach), } & \text { ss } \\ \text { tc } \\ \text { di is the only manageable method of presenting } & \text { rre }\end{array}$ multiple formats."

hi

under a multiple record process.

John F. Myers, Catalog Librarian

Schaffer Library, Union College

Posted on Autocat 11 December 2008 
Apart from fixed fields (which your OPAC may or may not apply), one record needs a gmd and one does not. That is sufficient reason for us to create two records. Unless you wish to introduce compound gmds, e.g., $245 \$$ h[text \& electronic resource], I would suggest two records.

That's wr-

While CO

“Apart from fixed fields ... one record sufficient reason for us to create two records.”

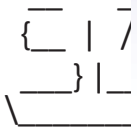

Posted on Autocat 11 December 2008

Amy: In the long run I think it's best to have separate records as it facilitates batchloading eresource MARC records from vendors and publishers, and it parallels what is done with services like Serials Solutions and ebrary.

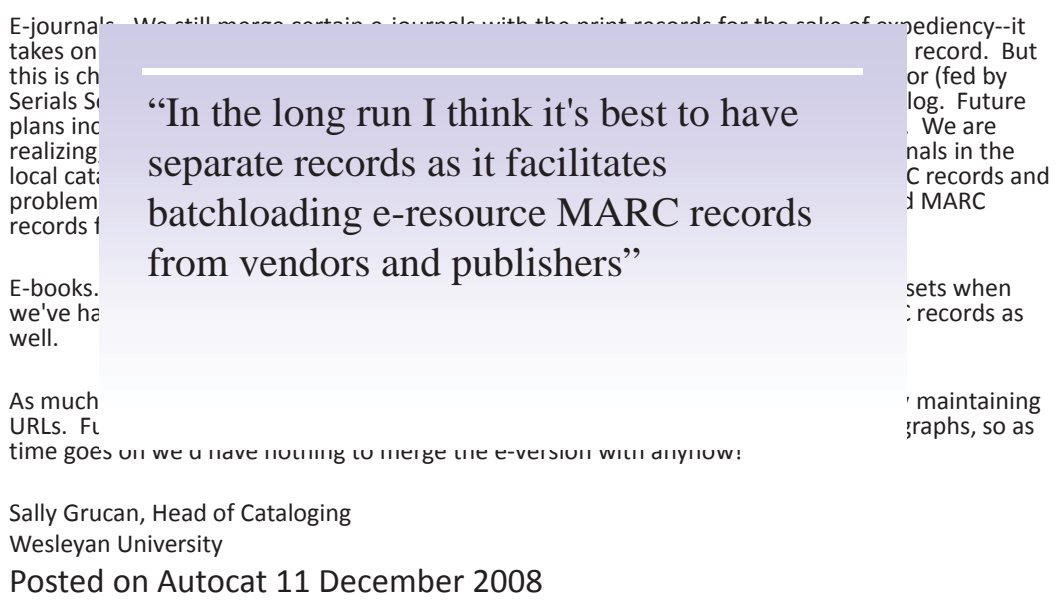




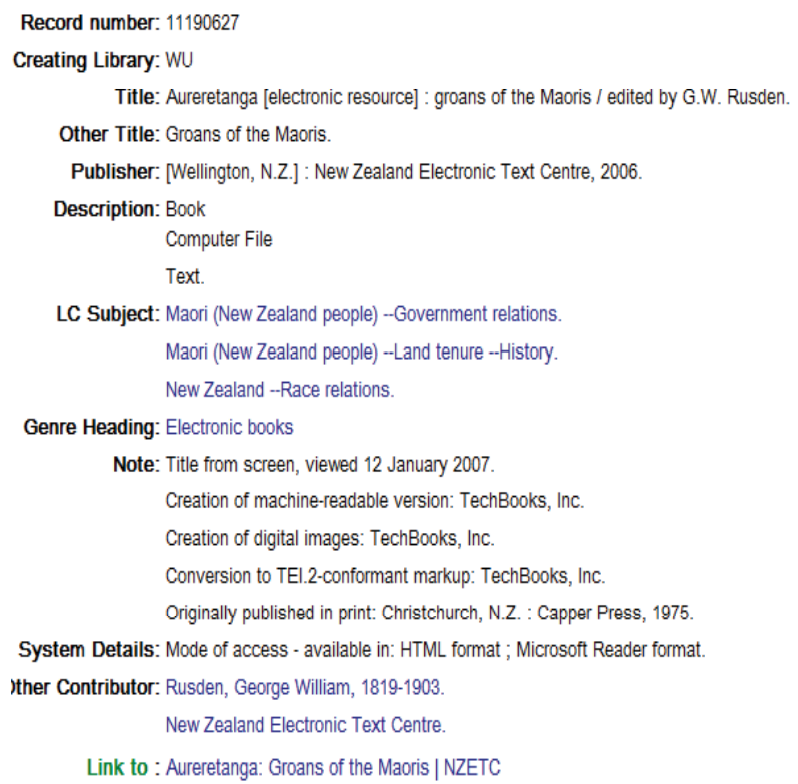

Link to : Aureretanga: Groans of the Maoris | NZETC

You are using WebCat National Bibliographic Database

Search Request: Advanced = (earliest AND new AND zealand) [in Title] AND (butler)[in Author Name] Search Results: Displaying 1 through 3 of 3 entries.

$$
\#
$$

Earliest New Zealand [electronic resource] : the journals and correspondence of the Rev. Butler, John, 1781 [Wellington, N.Z.] : New Zealand Electronic n „ John Butler / compiled by RJ. Barton.

-1841. Text Centre, [2007]

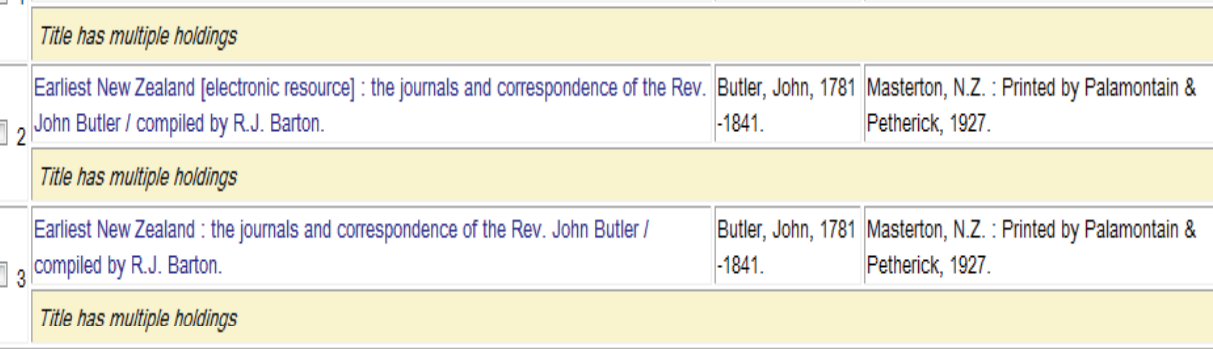


Earliest New Zealand the journals and correspondence of the Rev. John.

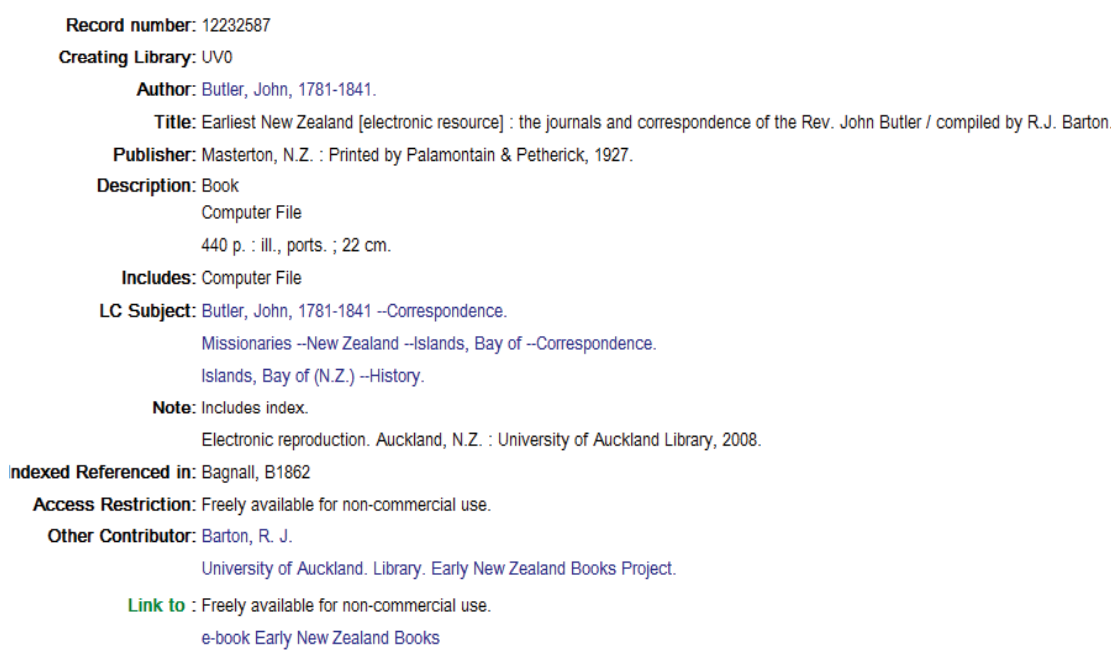

In anticipation of an implementation date of August 1, 2009, the Provider-Neutral E-Monograph MARC Record Guide has been posted to the BIBCO Web site: http://Www.loc.gov/catdir/pcc/bibco/PN-Guide.pdf. Thanks to Provider Neutral Task Force members Becky Culbertson, Yael Mandelstam, and George Prager or preparing the guide. The document contains

There is a link to the Provider-Neutral E-Monograph MARC Record Guide on the BIBCO Web site, listed under the BIBCO Partici

The P
2009 I $^{2}$ "In anticipation of an implementation date from:
revise
ref August 1, 2009, the Provider-Neutral E-Monograph MARC Record Guide has (cSR) qualif been posted to the BIBCO Web site"

LCRI 2 an update of the PCC Issue:

Thank for online series ine monographic Jger's Desktop 2009

Sincerely,

Les Hawkins

CONSER Coordinator

Library of Congress

lhaw@loc.gov

Posted on Autocat, 1 August 2009 
http://www.loc.gov/catdir/pcc/bibco/PN-Guide.pdf

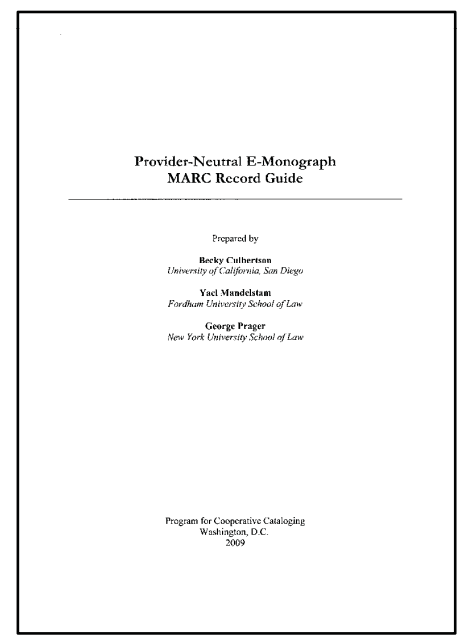

\section{Definition}

A provider-neutral e-monograph record is a single bibliographic record that covers all equivalent manifestations of an online monograph. Manifestations are considered equivalent if their format and their content are essentially the same, based on clues from the author, title, edition, publishing information, and physical description. Another separate record is needed only if the cataloguer determines that another online version, because of substantial differences (e.g., in content or subject), really represents a different manifestation. There will also be some cases where the resources are considered equivalent even though the titles that appear on each resource differ.

http://www.loc.gov/catdir/pcc/bibco/PN-Guide.pdf p. 10 
What are the types of online monographs for which it is used?

The provider-neutral e-monograph record has been defined for monographs that have the same content available by one or more providers. The monographs may be issued as born-digital resources, current simultaneously-issued-withprint editions, or scanned reproductions of previous existing materials. A provider-neutral record should be created for online monographs even if no equivalent manifestations exist at the point of cataloguing.

http://www.loc.gov/catdir/pcc/bibco/PN-Guide.pdf p. 10

\section{Why do we need it?}

Current monographic cataloging practice in the AngloAmerican world requires the creation of a new record each time a new publisher, aggregator, or distributor provides online access to the same electronic resource. As a result, many duplicative MARC records for online resources are created in shared cataloging systems such as OCLC. Catalog users often have difficulty understanding the rationale or the subtle differences between multiple records when searching through a cluster of very similar electronic resource records. The creation of one record that can be used for as many aggregations as possible will improve search and retrieval in online catalogs. Moving to the provider-neutral model puts the emphasis on the content of the resource, and not the provider. 


\section{Sample records}

- Available on OCLC WorldCat using the title search:

Provider Neutral Task Force example records

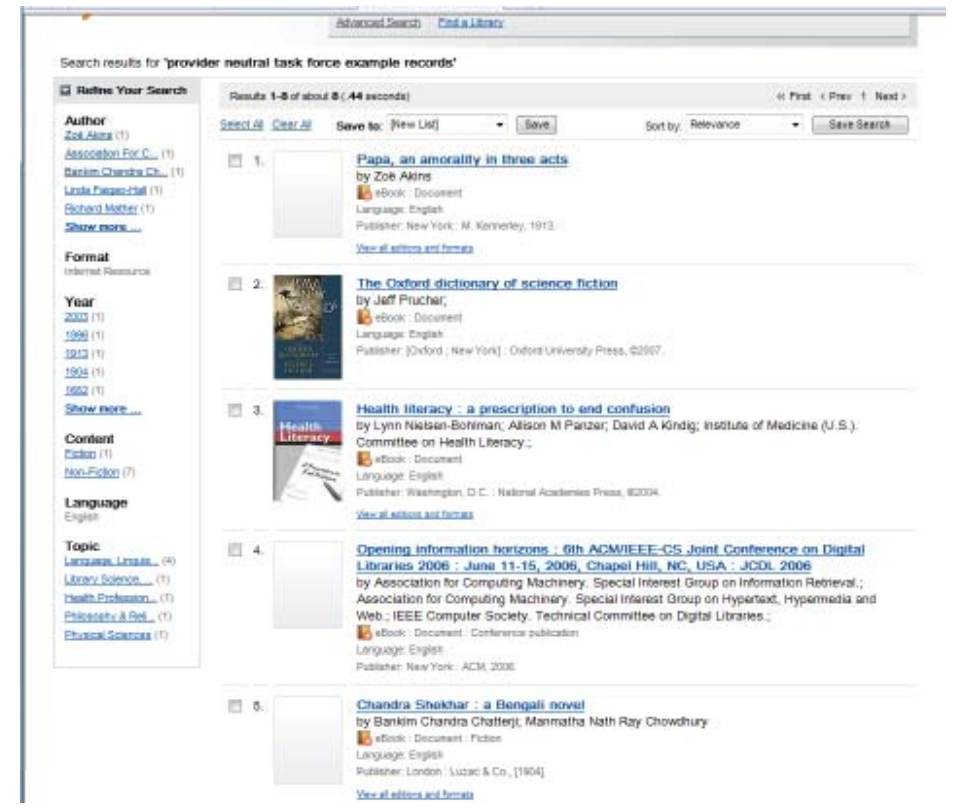




\section{Information codes}

Code 's' for form of item in position 23

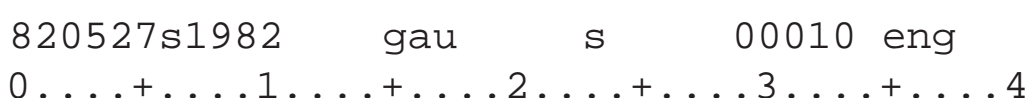

\section{LCCN}

Print LCCN moved to 776 field

\section{ISBN}

Use \$z for any ISBN other than the one specifically for the eBook

\section{0/082 Classification fields}

Use of classification strongly encouraged but not required 


\section{Title}

Use \$h[electronic resource]

24510 \$aEarliest New Zealand\$h[electronic resource] : \$bthe journals and correspondence of the Rev. John Butler /\$c compiled by R.J. Barton.

\section{Edition statement}

Use edition statement from original print source 
260 Publication, distribution, etc.

Use information from original print source

260 \#\# \$aMasterton, N.Z. : \$bPrinted by Palamontain \& Petherick, \$c1927.

\section{Physical description}

- Use \$a1 online resource

- Do not use \$c

300 \#\# \$a1 online resource (440 p.) :\$bill. 


\title{
Series fields
}

\author{
Used if on original resource
}

\section{General note}

500 \#\# \$aDescription based on print version record.

Or

500 \#\# \$aTitle from ...

"Prefer field 588 for this information once it has been implemented by OCLC" http://www.loc.gov/catdir/pcc/bibco/PN-Guide.pdf p. 6 


\title{
588 Source of Description (R)
}

New field

1st indicator b/ Undefined

2nd indicator b/ Undefined

Subfields $\quad \ddagger$ a Source of description note (NR)Note

containing administrative information about the record, such as source of description or latest issue consulted.

¥5 Institution to which field applies (NR)MARC code of the institution or organization that holds the copy to which the data in the field applies. Data in the field may not apply to the universal description of the item or may apply universally to the item but be of interest only to the location cited. See Organization Code Sources (http://www.loc.gov/marc/bibliographic/ecbdorg.html).

¥6 Linkage (NR)

Indexing Field 588 is not indexed.

OCLC Technical bulletin 258, May 2010

http://www.oclc.org/support/documentation/worldcat/tb/258/258.pdf

\section{Citations/reference note}

\author{
Use information related to the original print source
}

510 4\# SaBagnall, \$cB1862 
Do not use, use $776 \mathbf{\$ i}$ instead

533 Reproduction note

534 Original version note

538 System details note

540 Terms governing use and reproduction note

Do not use 


\section{Additional physical form}

Use to record information on the original resource

77608 \$iPrint version:\$aButler, John, 1781-1841.\$tEarliest New Zealand: the journals and correspondence of the Rev. John Butler.\$dMasterton, N.Z. : Printed by Palamontain \& Petherick, 1927.

\section{Electronic location and access}

Indicator 2 is 0 - Resource

85640 \$uhttp://WWW.nzetc.org/tm/scholarly/metadata-teiBarEarl.html \$ze-Book New Zealand Electronic Text Centre

85640 \$uhttp://WwW.enzb. auckland.ac.nz/document?wid=1455\&p=1\$ze Book Early New Zealand books 
Local decisions to aid searching:

655 Genre/Form heading

655 \#\# \$aElectronic books

Or

655 \#\# \$aElectronic journals

710

Corporate name heading

Name of corporate body supplying electronic text. NOT PROVIDER NEUTRAL!

710 2\# New Zealand Electronic Text Centre

\section{In the record for the original work}

Add the following information

\section{Additional form available note}

530 \#\# \$aAlso available via the World Wide Web. 


\section{Electronic location and access}

Indicator 2 is 1 - Version of resource

85641 \$uhttp://WWw.nzetc.org/tm/scholarly/metadata-teiBarEarl.html \$ze-Book New Zealand Electronic Text Centre

85641 \$uhttp://Www.enzb.auckland.ac.nz/document?wid=1455\&p=1\$zeBook Early New Zealand books

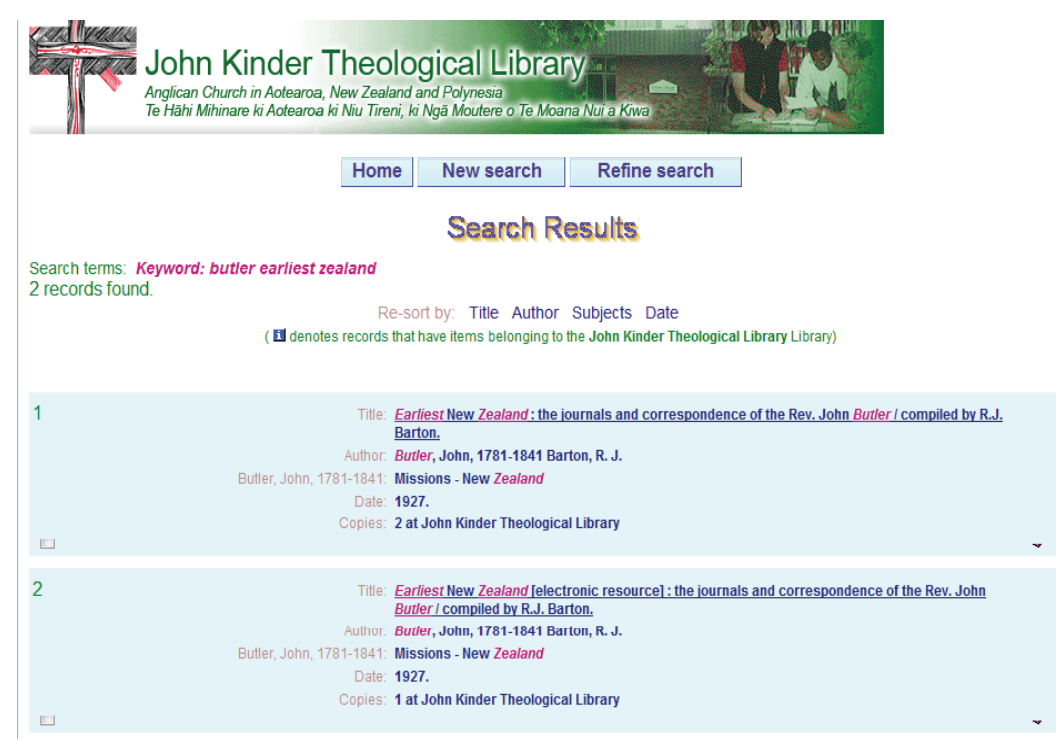



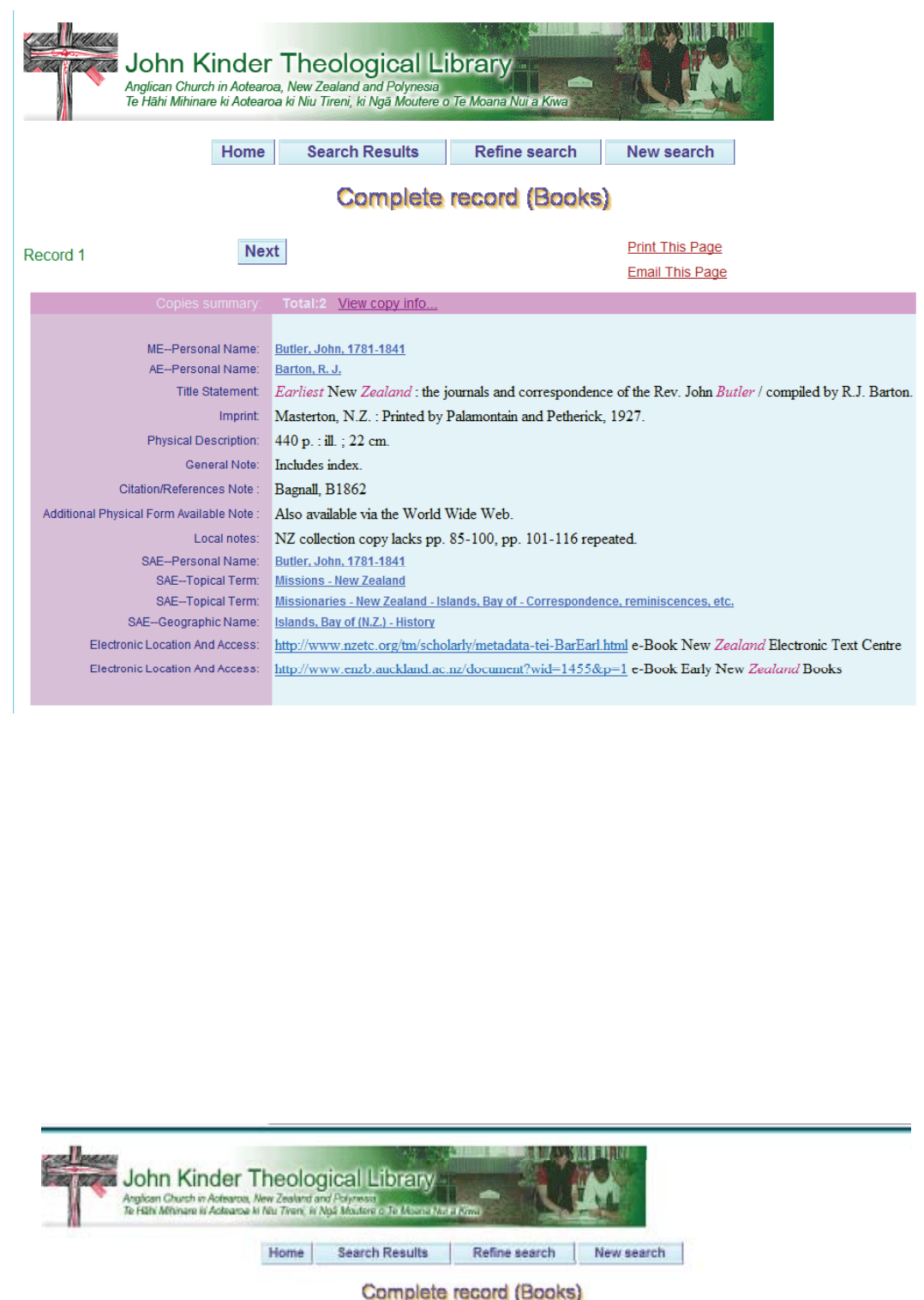

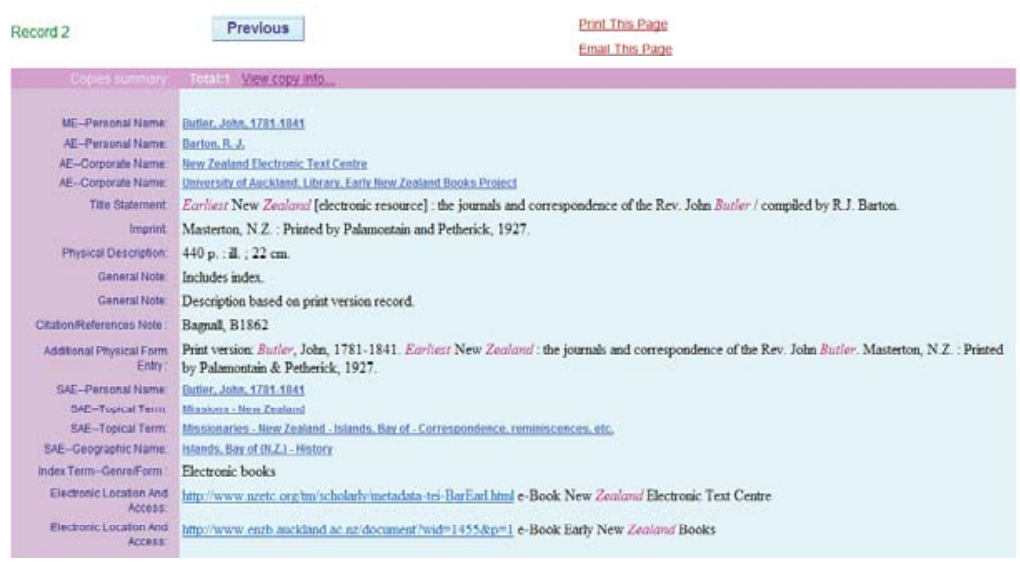

